\title{
Extraction of a Lost Intra-Aortic Balloon Pump Guidewire
}

\author{
Manouchehr Hekmat ${ }^{1}$, Hamid Ghaderi ${ }^{2,}$, , Seyedeh Adeleh \\ Mirjafari $^{3}$, Mehran Shahzamani ${ }^{2}$, Gholamreza Masoumi ${ }^{4}$
}

${ }^{1}$ Department of Cardiovascular Surgery, Shahid Modarres Hospital, Shahid Beheshti University of Medical Sciences, Tehran, Iran

${ }^{2}$ Department of Cardiovascular Surgery, Chamran Heart Center Hospital, Isfahan University of Medical sciences, Isfahan, Iran

${ }^{3}$ Tehran University of Medical Sciences, Tehran, Iran

${ }^{4}$ Department of Cardiac Anesthesiology, Chamran Heart Center Hospital, Isfahan University of Medical sciences, Isfahan, Iran

* Corresponding author: Hamid Ghaderi, MD, Department of Cardiovascular Surgery, Chamran Heart Center Hospital, Isfahan University of Medical sciences,

DOI: $10.21859 / \mathrm{ijcp}-03105$ Isfahan, Iran.E-mail: hghaderi@razi.tums.ac.ir

Submited: 12-19-2017

Accepted: 01-02-2018

Keywords:

Catheterization

Intra-Aortic Balloon Pump

Guidewire Methods

(C) 2018. International Journal of Cardiovascular Practice.

\begin{abstract}
Guidewire loss is a serious complication that in case of a complete wire loss could cause death in about $20 \%$ of cases. Although it is essential to retrieve an intravenous foreign body as soon as possible, there are only a few recommendations regarding the removal of an intra-arterial foreign body. This study reports on a rare complication of guidewire loss during the insertion of an Intra-Aortic Balloon Pump (IABP), which has not yet been reported in the literature. The approach to this problem has been described, including the extraction time and the technique.
\end{abstract}

\section{INTRODUCTION}

The Seldinger technique that was primarily used during radiographic approaches is currently used to perform different procedures, such as the placement of central venous catheters, hemodialysis catheters, and arterial catheters $[1,2]$. Although percutaneous catheterization is a routinely performed technique, it requires highly experienced and qualified personnel for attending to technical details to minimize complications. As any other invasive procedure, this technique is also associated with certain risks and complications. Although these complications have been rarely reported in correlation with a guidewire, if they occur, they can lead to serious morbidity or even mortality. Different methods are used for the extraction of an intravascular foreign body, such as a goose neck snare [3], Dormia basket [4], two-wire technique or biopsy forceps 6-F [5], and finally surgical interventions. This study reports a rare complication of guide wire loss during the insertion of an Intra-Aortic Balloon Pump (IABP), which has not yet been reported in the literature. This study explains the approach to this problem, including the extraction time and the technique.

\section{CASE PRESENTATION}

The patient was a 64-year-old male, who underwent Coronary Artery Bypass Graft (CABG) surgery for his coronary artery disease. At the end of the surgery, a decision was made for IABP insertion due to low cardiac output. The procedure was initiated through the Seldinger technique over the right common femoral artery. Unfortunately, before the guidewire appeared at the end of the balloon catheter, the surgeon inserted the catheter into the femoral artery and advanced it completely and the assisting technician did not inform about the loss of the guidewire. On routine chest X-ray control at the Intensive Care Unit (ICU), the surgeon noticed rolling of the guidewire in the thoracic aorta (Fig 1).

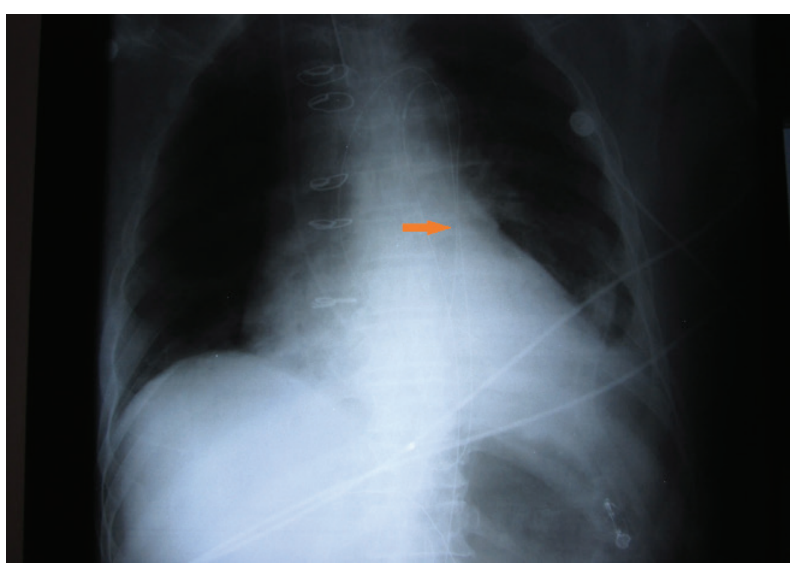

$\overline{\text { Figure 1: CXR showing a Misplaced Guidewire and the Placement }}$ of IABP 
Although the literature recommends the extraction of any intravenous foreign body as soon as possible, in the current case, the guidewire remained in the artery for 3 days and was not extracted due to the patient's critical condition, which necessitated the insertion of an IABP. During these 3 days, there was no arrhythmia or balloon catheter failure. Continuous infusion of heparin was used throughout the duration of the IABP insertion procedure to maintain the ACT between 150 and 200. Before 6 hours of IABP weaning, the heparin infusion was stopped and intravenous inotrope injection was decreased to the lowest dose. Some interventionists consider full anticoagulation using heparin before and during the extraction of a misplaced guidewire [6]. The technique described in this report could be used for the extraction of a misplaced guidewire as follows. After releasing the fixation sutures around the balloon sheet, we deflated the balloon and then applied one clamp over the balloon catheter just near the skin (it was clamped within the balloon catheter near the skin); thereafter, the clamp and the catheter were pulled back together. After the extraction of $10 \mathrm{~cm}$ of the catheter, the clamp was released and reapplied over the catheter near the skin and another $10 \mathrm{~cm}$ of the catheter was pulled back. This maneuver was repeated multiple times until the complete catheter and the inside guidewire were removed. The patient was discharged from the hospital without any complications after 8 days.

\section{DISCUSSION}

Central venous catheterization complications have been reported in about $12 \%$ of cases [7-9]. Wire breakage has been reported to occur in about $0.1 \%$ of venous catheterization cases [10], yet no data have yet been reported regarding other intravascular catheter failure complications [11]. Guidewire loss is a serious complication that in case of a complete wire loss, could cause death in about $20 \%$ of cases [12]. Although it is important to retrieve any intravenous foreign body as soon as possible [11], only a few recommendations are available regarding the extraction of an intra-arterial foreign body. The first report of the removal of an intravascular foreign body was described in 1964 [13]. Although the Seldinger technique has been commonly used by surgeons and interventionists for IABP insertion, it requires skilled personnel and a focus on the details through team work and close communication between group members to reduce the complications. The loss of a guidewire during IABP insertion is a preventable complication. The surgeon should place the guidewire at the proximal end of the balloon catheter during the entire time while advancing the catheter into the artery to prevent pushing of the guidewire into the vessel. The current technique could be easily applied to extract a misplaced guidewire in case such complication occurs.

\section{CONFLICT OF INTEREST}

None.

\section{REFERENCES}

1. Latto I, Ng W, Jones P, Jenkins B. Percutaneous Central Venous and Arterial Catheterization. London, Edinburgh, New York, Philadelphia, St Louis, Sydney, Toronto: WB Saunders; 2000.

2. Seldinger SI. Catheter replacement of the needle in percutaneous arteriography. A new technique. Acta Radiol Suppl (Stockholm). 2008;434:47-52. DOI: 10.1080/02841850802133386 PMID: 19023715

3. Yedlicka JW, Jr., Carlson JE, Hunter DW, Castaneda-Zuniga WR, Amplatz K. Nitinol gooseneck snare for removal of foreign bodies: experimental study and clinical evaluation. Radiology. 1991;178(3):691-3. DOI: 10.1148/radiology.178.3.1994404 PMID: 1994404

4. Dondelinger RF, Lepoutre B, Kurdziel JC. Percutaneous vascular foreign body retrieval: experience of an 11-year period. Eur J Radiol. 1991;12(1):4-10. PMID: 1999209

5. Dowais A, Hayeg O, Samei H. Loss of guide wire, a rare completely avoidable complication of central venous catheterization. Internet J Surg. 2009;21:1.

6. Kessel D, Robertson I. Interventional Radiology: A Survival Guide. 2nd ed. London: Churchill Livingstone; 2000.

7. Mansfield PF, Hohn DC, Fornage BD, Gregurich MA, Ota DM. Complications and failures of subclavian-vein catheterization. N Engl J Med. 1994;331(26):1735-8. DOI: 10.1056/ NEJM199412293312602 PMID: 7984193

8. Mitchell SE, Clark RA. Complications of central venous catheterization. AJR Am J Roentgenol. 1979;133(3):467-76. DOI: 10.2214/ ajr.133.3.467 PMID: 111506

9. Slany J, Karnik R. [Complications of routine intensive care interventions]. Wien Klin Wochenschr. 1994;106(1):1-7. PMID: 8135025

10. Burri C, Henkemeyer H, Passler HH. [Catheter embolism]. Schweiz Med Wochenschr. 1971;101(44):1575-7 contd. PMID: 5141578

11. Potgieter HF, Loggenberg E. Endovascular foreign objects retrieved by interventional radiologists at Universitas Hospital. South Afr J Radiol. 2004;8(2). DOI: 10.4102/sajr.v8i2.131

12. Heberer M, Moser J, Durig M, Harder F. [Prospective study of complications of central venous catheters]. Infusionsther Klin Ernahr. 1984;11(5):254-61. PMID: 6439638

13. Thomas J, Sinclair-Smith B, Bloomfield D, Davachi A. Non-Surgical Retrieval of a Broken Segment of Steel Spring Guide from the Right Atrium and Inferior Vena Cava. Circulation. 1964;30:106-8. PMID: $\underline{14197828}$ 